\title{
ON THE PECULIARITIES OF THE RING CONTRACTION REACTIONS OF HOMODRIMANES VIA ACID MEDIATED EPOXIDE REARRANGEMENT
}

\author{
Veaceslav Kulciţki*, Tatiana Sîrbu, Nicon Ungur \\ Institutul de Chimie al AŞ a RM, str. Academiei, 3, MD-2028, Chişinău, Republica Moldova \\ *Correspondingauthor:kulcitki@yahoo.com
}

\begin{abstract}
A selective rearrangement of a epoxi-homodrimanic substrate is described. Using fluorosulfonic acid at low temperature leads by ring contraction to a perhydrindanic structure. On the contrary, using boron trifluoridediethyl ether at r.t. selectively brings about angular methyl migration.
\end{abstract}

Keywords: terpenoids, homodrimane, epoxide, rearrangement, hydrindane.

\section{Introduction}

Rearrangement reactions of terpenoids leading to ring contraction represent a generally accepted biosynthetic pathway to diverse natural compounds. In general, these reactions are supposed to proceed via an acid-mediated epoxide rearrangement. For a series of important classes of terpenes such biosynthetic schemes have been postulated. We have used a similar bio-mimetic approach [1] for the synthesis of austrodoric acid $\mathbf{1}$ - a ring contracted nor-drimanic sesquiterpenoid isolated from the Dorid nudibranch Austrodoris Querguelenensis. The key step of the synthesis was a bio-mimetic ring contraction of a homodrimanic substrate 2 . This step was performed under the action of a Lewis acid and the yield of target perhydrindane 3 was moderate (cca. $45 \%$ ). The structure of the minor reaction products was not reported in our paper and it was the subject of following discussions [2]. We present in the current communication our first results on identification of the minor rearrangement products, which resulted from deeper skeleton transformations of epoxide 2 (Scheme 1).

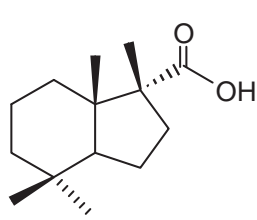

1

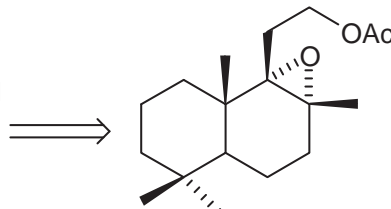

2

\section{Results and discussion}

Rearrangement reaction of epoxides, leading to ring contraction are supposed to proceed via a process, involving acidic attack on the epoxy-group, followed by epoxide opening. A carbonium ion is formed as a result, and its stability assures the following reaction course. Electron-donating groups facilitate carbonium ions formation and in the case of unsymmetrically substituted epoxides, the carbonium ion which is more stabilized by these groups is favoured. In our case, the epoxide group in the substrate $\mathbf{2}$ is attached to similar substituted carbons, and it is very difficult to estimate the localisation of the positive charge after acidic attack. Consequently, different reaction pathways can lead to different products, diminishing the reaction selectivity.

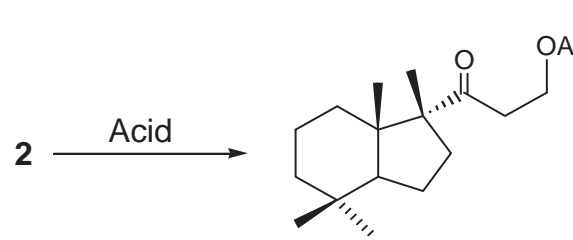

3

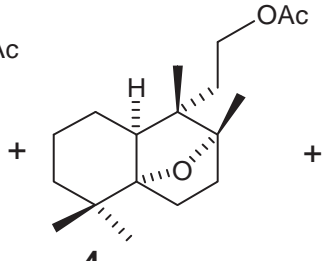

4<smiles>C=C1CCC2=C(CC[CH+]C2(C)C)[C@@]1(C)CCO</smiles><smiles>CC(=O)OCC[C@@]1(C)C2=C(CC[C@@]1(C)O)C(C)(C)CCC2</smiles>

6

Scheme 1

We have investigated the reaction of epoxide 2 with different acids. All experiments led to similar reaction products, consisting of mixtures of several compounds (Scheme 1). The product composition was also affected by the reaction temperatures and durations. It was established, that the best yield of ring contraction product 3 was highest on treatment of 2 with fluorosulfonic acid at $-78^{\circ} \mathrm{C}$ for $15 \mathrm{~min}$, followed by quenching with triethylamine-hexan mixture. 
Using boron trifluoride-diethyl ether complex as initiator turned out to provide selectively the rearranged diene 5 in a similar $66 \%$ yield. Formation of minor amount of 3 was also detected. The results of all isomerisation experiments are presented in the Table 1 below. The relative ratio between reaction products was determined on the basis of ${ }^{1} \mathrm{H}$ NMR data of crude reaction mixtures, by integration of selective proton signals (Figure 1). Separation of individual compounds was performed chromatographically. Structural assignment was performed on the basis of ${ }^{1} \mathrm{H}$ and ${ }^{13} \mathrm{C}$ data of pure compounds, as well as on the basis of IR spectra. Compound $\mathbf{4}$ was characterized as free alcohol 7, obtained after hydrolysis $\left(\mathrm{K}_{2} \mathrm{CO}_{3}-\mathrm{MeOH}\right)[3]$.

Table 1

\begin{tabular}{|c|c|c|c|c|c|c|c|c|}
\hline \multirow{2}{*}{$\begin{array}{l}\text { Exp. } \\
\text { No }\end{array}$} & \multirow[b]{2}{*}{ Solvent } & \multirow{2}{*}{$\begin{array}{c}\text { Reaction } \\
\text { Temperature, } \\
{ }^{\circ} \mathrm{C}\end{array}$} & \multirow{2}{*}{$\begin{array}{l}\text { Reaction } \\
\text { duration, } \\
\quad \text { min }\end{array}$} & \multicolumn{4}{|c|}{ Reaction product distribution, $\%$} & \multirow[b]{2}{*}{ Acid } \\
\hline & & & & 3 & 4 & 5 & 6 & \\
\hline 1 & $\mathrm{DCM}$ & -20 & 35 & 45 & 14 & 18 & n.d. & $\mathrm{BF}_{3} \cdot \mathrm{Et}_{2} \mathrm{O}$ \\
\hline 2 & $\mathrm{MeNO}_{2}$ & -25 & 15 & 50 & 17 & 33 & n.d. & $\mathrm{BF}_{3} \cdot \mathrm{Et}_{2} \mathrm{O}$ \\
\hline 3 & $\mathrm{MeNO}_{2}$ & 0 & 20 & 47 & 35 & 19 & n.d. & $\mathrm{BF}_{3} \cdot \mathrm{Et}_{2} \mathrm{O}$ \\
\hline 4 & $2-\mathrm{NO}_{2}-\mathrm{Pr}$ & 22 & 15 & 35 & n.d. & 66 & n.d. & $\mathrm{BF}_{3} \cdot \mathrm{Et}_{2} \mathrm{O}$ \\
\hline 5 & $\begin{array}{l}\mathrm{MeNO}_{2}+2-\mathrm{NO}_{2}- \\
\operatorname{Pr}(1: 1)\end{array}$ & $-78 \div-40$ & 45 & 54 & 18 & n.d. & 27 & $\mathrm{BF}_{3} \cdot \mathrm{Et}_{2} \mathrm{O}$ \\
\hline 6 & $\begin{array}{l}\mathrm{MeNO}_{2}+2-\mathrm{NO}_{2}- \\
\operatorname{Pr}(1: 1)\end{array}$ & -50 & 15 & 51 & 28 & n.d. & 22 & $\mathrm{BF}_{3} \cdot \mathrm{Et}_{2} \mathrm{O}$ \\
\hline 7 & $2-\mathrm{NO}_{2}-\mathrm{Pr}$ & -78 & 15 & 65 & 35 & n.d. & n.d. & $\mathrm{FSO}_{3} \mathrm{H}$ \\
\hline 8 & $\mathrm{DCM}$ & 22 & 60 & 45 & 20 & 35 & n.d. & $* \mathrm{R}-\mathrm{SbCl}_{6}$ \\
\hline
\end{tabular}

*R=tris-(p-bromophenyl)-aminium

Explanation of these results can be made on mechanistical grounds. In order for the substrate 2 to form a ring contracted product, the acid attack on the epoxy-group shall lead to formation of C-8 carbonium ion A (Scheme 2). It is stabilized by three alkyl groups and by neighbouring acetoxy- group. Following disruption of C9-C10 bond and formation of the new $\mathrm{C} 10-\mathrm{C} 8$ bond occurs through the tri-centered cation and after proton expulsion provide the ring contracted perhydrindane 3 .

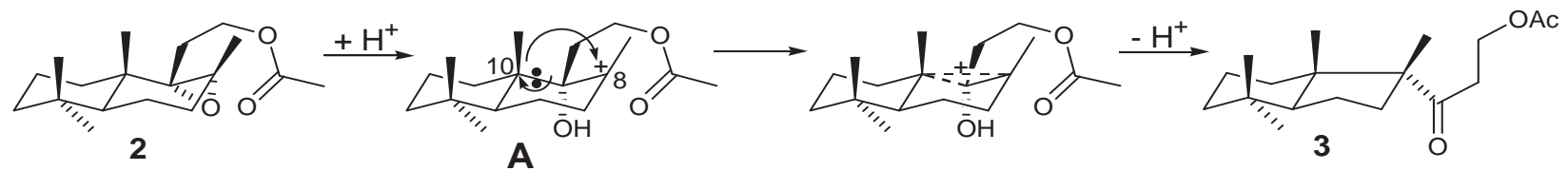

Scheme 2

The other reaction pathway is represented in Scheme 3. Carbonium ion formation occurs at C9, which is also facilitated by three alkyl substituents, but less likely stabilized by acetoxy-group. Instead, it is facilitated by the equatorial disposal of the $-\mathrm{OH}$ group and by a facile methyl migration from $\mathrm{C} 10$ to $\mathrm{C} 9$, to give intermediate carbocation B. It can transform either by a following hydride shift and cyclisation through the C8-O- atom into oxide 4 , or by deprotonation to 5 and $\mathbf{6}$.

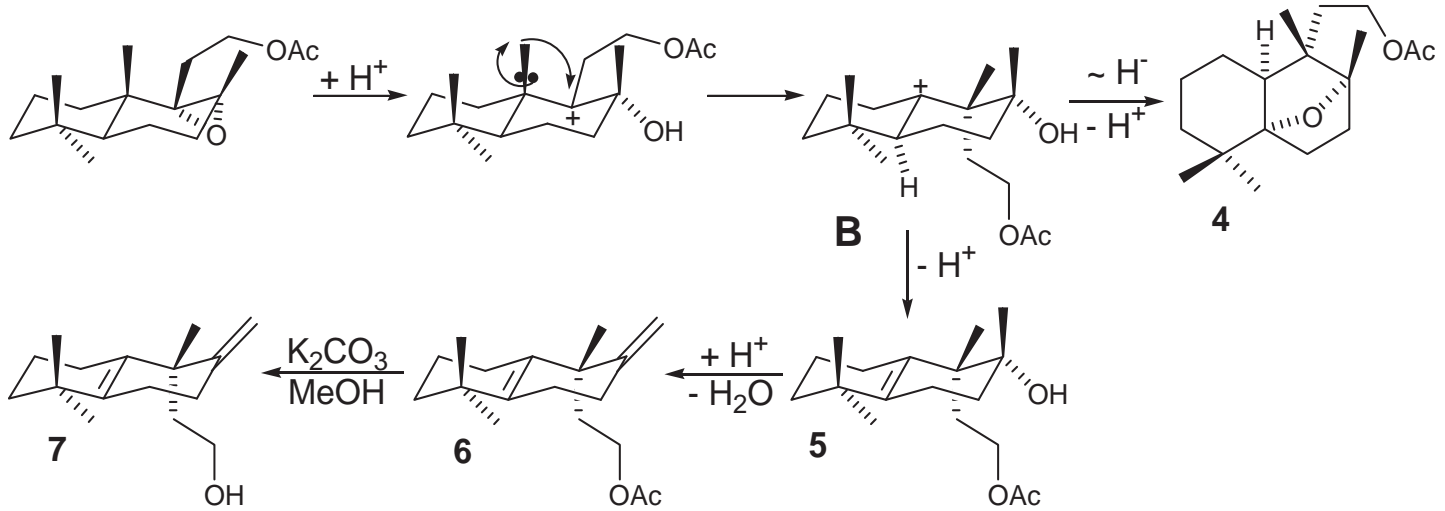

Scheme 3 


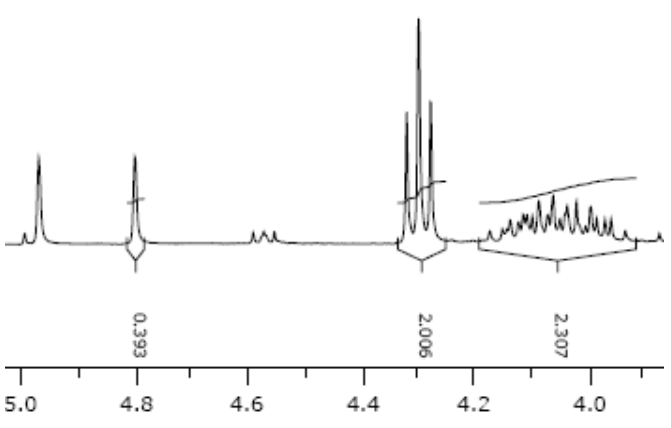

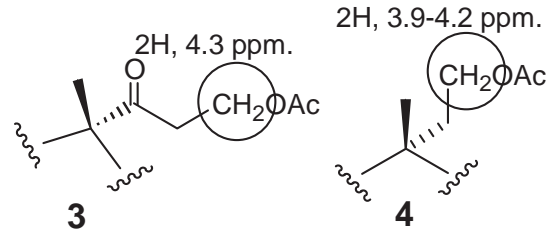

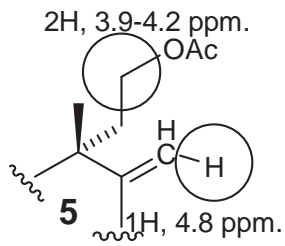

Figure 1. Determination of the isomeric product distribution by integration of selective NMR peaks (experiment No 3). Peak at $4.8 \mathrm{ppm}$ corresponds to one proton of 5 , the triplet at $4.3 \mathrm{ppm}$ - to two protons of $\mathbf{3}$ and the multiplet 3.9-4.2 represents additive signals from two $\mathrm{CH}_{2}$-groups of compounds 4 and 5 .

\section{Conclusions}

By using different acid inducers and reaction conditions it was possible to finely tune the selectivity of homodrimanic epoxide rearrangements, which besides ring contraction, involve a cascade epoxide opening, followed by methyl and proton shifts. The observed mechanism of epoxide 2 reactivity is confirmed by the similar results in the known transformation of bisnor-labdanic epoxides, reported previously by Halsall and Hadley [4].

\section{Acknowledgements}

V.K. acknowledges Alexander von Humboldt foundation for a postdoctoral fellowship.

\section{References}

[1]. Kulcitki, V.; Ungur, N.; Gavagnin, M.; Carbone, M.; Cimino, G. Tetrahedron: Asymm., 2004, 15 (3), $423-428$.

[2]. Alvarez-Manzaneda, E.; Chahboun, R.; Barranco, I.; Cabrera, E.; Alvarez, E.; Lara, A.; Alvarez-Manzaneda, R.; Hmamouchic, M.; Es-Samti, H. Tetrahedron, 2007, 63, 11943-11951.

[3]. Compound 3. ${ }^{1} \mathrm{H}$ NMR $\left(\mathrm{CDCl}_{3}, 300 \mathrm{MHz}\right)$ : 4.31 (t., 2H, J=6Hz), 2.6-2.9 (m., 2H); 2.15-2.25 (m., $\left.1 \mathrm{H}\right) ; 2.00$ (s., 3H); 1.17 (s., 3H); 0.87 (s., 3H); 0.86 (s., 3H); 0.84 (s., 3H). IR (liquid film, cm-1): 1734, 1695.

Compound 5. ${ }^{1} \mathrm{H}$ NMR ( $\left.\mathrm{CDCl}_{3}, 300 \mathrm{MHz}\right): 5.00$ (s., 1H); 4.83 (s., 1H); 3.96-4.15 (m., 2H); 2.02 (s., $3 \mathrm{H}$ ); 1.10 (s., 3H); 1.04 (s., 3H); 1.03 (s., 3H). IR (liquid film, cm-1): 2925, 1742, 1460, 1364, 1234, 1034, 880.

Compound 6. ${ }^{1} \mathrm{H}$ NMR ( $\left.\mathrm{CDCl}_{3}, 300 \mathrm{MHz}\right)$ : 4.08-4.27 (m., 2H); 2.03 (s., 3H); 1.14 (s., 3H); 1.00 (s., $\left.3 \mathrm{H}\right) ; 0.99$ (s., 3H); 0.97 (s., 3H). IR (liquid film, cm¹): 3460; 2927; 1737; 1461; 1364; 1239; 1142; 1082; 1031.

Compound 7. ${ }^{1} \mathrm{H}$ NMR (CDCl, $\left.300 \mathrm{MHz}\right): 3.69$ (t., 2H, J9Hz); 1.29 (s., 3H); 1.10 (s., 3H); 1.01 (s., $\left.3 \mathrm{H}\right) ; 0.76$ (s., 3H). IR (liquid film, $\mathrm{cm}^{-1}$ ): 3400; 2932; 2870; 1452; 1386; 1073; 1041.

[4]. Hadley, M. S.; Halsall, T. G. J. Chem. Soc. Perkin Trans. I, 1974, 1334-1349. 